Case Report

\title{
Multi-Drug Resistant Tuberculosis in a foreign resident visa holder and implications of a growing inbound migrant flow to Sri Lanka
}

\author{
K Wickramage $^{1}$, S Samaraweera ${ }^{2}$, S Peiris $^{1}$, J Elvitigala ${ }^{3}$, ATND Patabendige ${ }^{4}$ \\ Sri Lankan Journal of Infectious Diseases 2013 Vol.3(2):31-36 \\ DOI: http://dx.doi.org/10.4038/sljid.v3i2.5286
}

Key words: Migration health; tuberculosis; multi-drug resistance

\begin{abstract}
We present a case of an international labour migrant worker from India who acquired multipledrug resistant tuberculosis (MDR-TB) as a result of poor treatment compliance throughout his work and travel history. The travel to Sri Lanka was made under the resident visa scheme. Currently there are no mandatory health assessment requirements for inbound migrants such as resident visa holders to Sri Lanka. The diagnosis of MDR-TB was made at a district level chest clinic and the National Tuberculosis Program (NTP). This is the first documented case of MDRTB in a foreign born migrant worker in Sri Lanka. The volume of resident visa applicants and foreign migrant workers to Sri Lanka from high TB burden countries has increased dramatically over the past five years. We examine the rationale and public health impact for undertaking a health assessment of the growing numbers inbound migrant workers to Sri Lanka from high TB burden countries.
\end{abstract}

\section{Introduction}

International migration continues to be a major phenomenon of our modern era with more people on the move than any other time in human history. ${ }^{1}$ Tuberculosis (TB) is one of the most important diseases among foreign populations. ${ }^{2}$ Once infected with tubercle bacilli, a person has a lifetime risk of contracting the illness. Thus tuberculosis remains a major cause of ill health and death globally. ${ }^{3}$ The principal target of United Nations' Millennium Development Goals (MDGs) and the supplementary targets are to halve the TB prevalence and mortality rates by 2015 , as compared to 1990. The most important intervention for the control of tuberculosis (TB) is effective treatment of infectious cases. ${ }^{4}$ Failure to complete treatment poses a significant public health risk through disease reactivation, increased transmission, and development of drugresistance. About $24 \%$ of the world's population living in the South Asian region bears $30 \%$ of

\footnotetext{
${ }^{1}$ International Organization for Migration, Sri Lanka

${ }^{2}$ GFATM Project, Ministry of Health and National Programme for Tuberculosis Control \& Chest Diseases, Sri

Lanka

${ }^{3}$ National Tuberculosis Reference Laboratory, Sri Lanka

${ }^{4}$ District Tuberculosis Control Office, Matara, Sri Lanka
}

Address for correspondence: DrKolitha Wickramage. Health Unit. International Organization for Migration. No.62, Green Path, Colombo 3. Email: kwickramage@iom.int, Tel: +94 (0)77 2518740 
the disease burden in terms of incidence of TB cases. In India alone, about 1.8 million new episodes of disease accounted for one in every five cases in the world, making it first in the list of 22 High Burden Countries (HBCs) defined by WHO. ${ }^{5}$

Infection with Mycobacterium tuberculosis resistant to both rifampicin and isoniazid, with or without resistance to other anti-tuberculosis drugs, is defined as multi drug resistant tuberculosis (MDR-TB). ${ }^{6}$ MDR-TB is still relatively rare in Sri Lanka. Sri Lanka's success has been attributed to the effective National Tuberculosis Control Programme (NTP) which screens, diagnoses and treats the disease without incurring any cost to the patient. Sri Lanka has adopted the Directly Observed Treatment Short-course (DOTS) strategy in phases since 1997, covering the entire country by 2010. The central laboratory of the NTP has detected 25 cases of MDR-TB from year 2010 to 2012, all of which were indigenous cases. None of them were classified as extremely drug resistant TB (XDR-TB). There has been a reduction in the MDR-TB cases from 16 in 2005 to 4 cases in 2012. However, the threat still persists, since most cases of MDR-TB results from poor compliance and erratic treatment. ${ }^{7,8} \mathrm{~A}$ recent study also revealed the presence of evolved Beijing strains of $M$ tuberculosis among a relatively young cohort of patients. ${ }^{9}$ The Beijing strain is known for its ability to evade the protective effect of Mycobacterium bovis (BCG) vaccination, ${ }^{10}$ and be more prone to acquire drug resistance. ${ }^{11}$

\section{Case-report}

We report a case of MDR-TB in a 31 year old male ("SHR") from the district of Andra Pradesh, India, who travelled to Kuwait as an international labour migrant worker in 2006 to work as a driver. There he met and married a Sri Lankan female labour migrant working as a house maid. After 2 years they returned to his home in Andra Pradesh, where they lived for a year. While in India, SHR developed a long lasting cough, with intermittent low grade fever for which he did not seek any medical attention.

In the early months of 2009, with the intention of returning to Kuwait for work, SHR underwent mandatory medical screening as part of the work visa requirement at a GAMCA (Gulf Cooperation Council Approved Medical Centres' Association) approved medical center in India. Radiological findings revealed opacities suggestive of pulmonary TB. Sputum microscopic examination for acid fast bacilli (AFB) was also positive. Treatment with first line drugs (isoniazid, rifampicin, pyrazinamide and ethambutol (HRZE)) was initiated and continued for 2 months. The treatment was managed through a private sector provider in India. However the patient appears not to have completed the directly observed therapy (DOT) protocols for TB. At the end of the two months he was re-screened and as his sputum microscopy for AFB was negative, he was given the medical certificate to travel and work. According to his wife, he was not advised about continuing treatment up to 6 months, and they had assumed that the disease was now cured. Thus, despite "defaulting" DOTs treatment after 2 months, he left for Kuwait to work as a driver in 2009.

SHR worked in Kuwait for nearly two years before he developed severe chest pain, cough and fever. On worsening of his condition, he consulted a doctor in a private clinic. Radiological investigation suggested reactivation of TB. The state of Kuwait which falls under the jurisdiction of Gulf Cooperation Council (GCC) preserves the right to deport foreign migrant workers diagnosed with specified conditions such as HIV and TB. ${ }^{12,13}$ SHR immediately resigned from work and returned to India in November 2010 to commence TB treatment from a private sector 
provider. He continued DOTS treatment for two weeks, until he travelled to Sri Lanka with his wife and family. Since he was a national of India, he entered Sri Lanka on a tourist visa, and subsequently successfully obtained a residence visa under the "spouse of Sri Lankan" category.

From the second day of his arrival in Sri Lanka, he developed severe chest pain and presented to a government chest clinic in the southern district of Matara, Sri Lanka. A chest x-ray taken on 22nd November 2010 showed a cavity in the mid zone of the right lung and opacity in the mid zone of the left lung. The three samples of sputum taken on $22^{\text {nd }}$ and $23^{\text {rd }}$ were AFB positive (with a '+'grading). Sputum for culture and drug susceptibility testing were done due to his previous "defaulter" status. Though category II treatment was recommended according to Sri Lankan guidelines of TB management, ${ }^{14}$ due to a nation-wide shortage of intra-muscular streptomycin, the patient was treated with the category I first line oral agents (fixed dose isoniazid, rifampicin, pyrazinamide and ethambutol) daily from $26^{\text {th }}$ November 2010, given under direct medical observation at the nearest Government Hospital. On $29^{\text {th }}$ December 2010, the patient was referred to the district chest clinic, and the regime was changed to Category II, i.e. 2 months HRZE (isoniazid, rifampicin, pyrazinamide and ethambutol), plus streptomycin (1g daily), followed by one month of HRZE and finally for 5 months of HRE.

Since the patient developed haemoptysis, repeated sputum samples for AFB, chest X-ray and CT scan chest were done which revealed endo-bronchial TB. The TB culture, using Lowenstein Jenson medium, reported growth of Mycobacterium tuberculosis, with confluent growth of (3+)on $1^{\text {st }}$ March 2011. The drug sensitivity testing (DST) reported on $8^{\text {th }}$ March 2011 revealed MDR-TB resistant to streptomycin, INAH, rifampicin and ethambutol.

Screening of family members and those with close and frequent contacts with SHR was done. This is important, especially as he was identified as having MDR TB. SHR was not employed during his short stay in Sri Lanka and did not associate with many people due to the language barrier, thereby reducing the number of potential contacts. His house, situated in a village in a remote area of Matara, had three bedrooms with good ventilation through multiple open windows and with areas of direct sunlight. The two children slept in the same room with their parents. Chest X-ray of the children (5 year old boy, and 3 year old girl) and mother was nonsuggestive of TB.

According to TB management guidelines of Sri Lanka, the patient was referred to the National Chest Hospital at Welisara and counseled on the requirements for in-ward treatment at the same institution for a minimum of 6 months, including the requirement for follow up drug treatment for $18-24$ months as an outpatient. The patient refused to be treated in Sri Lanka, and according to his spouse was unhappy to be isolated for a long duration in a foreign country. SHR returned to India within one week of his MDR diagnosis to continue his treatment at a private hospital in Vellore.

\section{Discussion and Conclusions}

We report the first case of MDR-TB in a foreign born resident visa holder of Sri Lanka identified through the NTP program. Whilst many recognize Sri Lanka as a 'labour sending country 'with approximately 2 million migrant workers (or one in every ten Sri Lankans) working overseas, only a few are aware that the nation is increasingly becoming a 'labour receiving country' needing foreign workers to fuel the demands of a post-war developmental boom. ${ }^{15}$ This case- 
report serves as an important catalyst to identify both effective and humane strategies for TB detection and management for those non-citizens with long stay resident visas.

Population mobility across the world is rapidly becoming a key determinant in the epidemiology of tuberculosis. A meta-review on active screening at entry for tuberculosis among new immigrants to Europe documented that the proportion of screened immigrants with active pulmonary tuberculosis ranged between 1 and 38 per 1,000 , that is, between 10 to 100 times greater than the prevalence measured in the general population of the host country. ${ }^{16}$ Hence similar to this case, there may well be other cases of MDR-TB, considering the increasing volumes of inbound resident visa holders arriving in Sri Lanka to reside from TB endemic countries such as India and China. An analysis of data from the Immigration Controller General on resident visa holders to Sri Lanka for the year 2010 showed 9,815 Chinese and 9,702 Indian visa holders, comprising of $23.1 \%$ and $22.84 \%$ of the total inbound resident visa caseload. More recently, in February 2013, the government announced a scheme to formally grant work visas for Indian nationals to work to harvest paddy fields in Sri Lanka due to domestic labour shortages, ${ }^{17}$ who will be provided with three-month visas for work.

This reported case was detected only due to the patient's advanced clinical disease progression which led to a self-referral to a government chest clinic. The surveillance mechanism established by the NTP does not capture cases from foreign migrant populations. There are also no health assessment requirements established in Sri Lanka for assessing TB status of resident visa applicants (at time before departure and/or at port of entry and/or after settlement), such as those performed in other countries in the region such as Australia, ${ }^{18}$ Singapore $^{19}$ and Malaysia. In the absence of a pre-departure health assessment at the country of origin of the migrant worker, an effective TB diagnostic screening capacity at peripheral locations, or through an outreach strategy where a mobile lab may enter work sites where large populations of foreign migrant workers are present, is essential.

Although the government is yet to enact a clear policy on treatment or screening of non-citizens for TB and other diseases of public health importance, at the time of writing, a cabinet paper for a health assessment for inbound resident visa holders was passed by Parliament. The cabinet paper provides a legal platform upon which to build technical instruction and outline a health assessment mechanism to ensure an evidence-based approach to manage health impacts due to inbound migration. The Ministry of Health in Sri Lanka is also in the process of developing a 'National migration health policy' through an inter-ministerial process, which seeks to ensure the right to health is protected for all migrant and mobile population groups, irrespective of legal status. $^{20}$

This case-report also highlights the need to determine clear policies and procedures on the consequences of a MDR-TB and XDR-TB management of foreign nationals detected with TB in Sri Lanka. The current practice adopted by the TB campaign is as per national treatment guidelines for which the foreign national will be required to undergo treatment at the specialist TB hospital at Welisara. The costs to Sri Lanka health care budget for treatment of a MDR-TB patient is approximately $\$ 10,000$ USD. The challenges /complications arise due to the need for housing and managing a foreign national for treatment duration of at least 4 to 6 months in the same facility until the patient becomes non-infectious (sputum negative). The Government of Sri Lanka is currently developing a policy and legal framework through a National migration health policy agenda to address the health assessment protocols and conditions for inbound resident 
visa holders and non-citizens. There is also the possibility that SHR may well have acquired a drug resistant strain during his stay in the Middle East. There are nearly 2 million Sri Lankan's working overseas as labour migrants, with a net outflow of approximately 300,000 per annum, or 730 leaving Sri Lanka per day. ${ }^{21}$ Ninety-three percent of migrant workers work in the Middle East, with the majority working in the Kingdom of Saudi Arabia. The large number of foreign workers in this region could also be a significant source of TB for Sri Lanka ${ }^{22}$, particularly of drug resistant strains, due to exposure from co-workers from high incidence countries and inadequate access to health care. TB forms non-admissibility criteria for obtaining employment and/or resident visa status in many parts of the world.

TB is deeply rooted in poverty and low socioeconomic status as well as legal, structural and social barriers which prevent meaningful TB prevention, diagnosis, treatment and care. ${ }^{23} \mathrm{~TB}$ screening for purposes of labour migration and immigration can indeed play a role in the early detection, treatment and care of those afflicted with the disease, if such health assessments are integrated with health systems and/or National TB programs of both sending/receiving countries. ${ }^{24}$ In the increasingly globalized village, with rapid population mobility across borders, tuberculosis continues to be a major public health issue, and a disease which lies at the fulcrum of individual patient rights, societal rights and the state responsibility to protect. The legislation and regulations laid down for Sri Lankans have to be followed for foreigners as well, since both indigenous and foreign nationals have equal rights and duties. This case report reminds us that implementation of high-quality DOT programs is a collective and shared global responsibility. It is crucial to ensure proper treatment of all $\mathrm{TB}$ patients, in order to prevent the emergence of MDR and XDR $M$ tuberculosis strains.

\section{References}

1. Swing, W.L. The State of Migration: current Realities, future frontiers. Proceedings of $100^{\text {th }}$ IOM Council Session, 5-7 December 2011:

Available:http://www.iom.int/jahia/webdav/shared/shared/mainsite/about_iom/en/council/100/M ICEM_4_2011.pdf Accessed: 27 August 2012

2. Tala, E. Tuberculosis care in foreigners: ethical considerations. European Respiratory Journal 1994;7(8):1395-96. doi:http://dx.doi.org/10.1183/09031936.94.07081395

3. Espinal, Marcos A., Adalbert Laszlo, Lone Simonsen, FadilaBoulahbal, Sang Jae Kim, Ana Reniero, et al. Global trends in resistance to anti-tuberculosis drugs. New England Journal of Medicine 2001: 344(17):1294-1303. doi: 10.1056/NEJM200104263441706

4. Abubakar, I., Lipman, M., Anderson, C., Davies, P., \&Zumla, A. Tuberculosis in the UK - time to regain control. BMJ. 2011; 343 doi: http://dx.doi.org/10.1136/bmj.d4281

5. WHO Global Tuberculosis Report 2012. (2012) WHO, Geneva, Publications. ISBN 97892 41564502

6. Iseman MD. Treatment of multidrug resistant tuberculosis. New England Journal of Medicine 1993;329:784-91 doi: http://dx.doi.org/10.1056/NEJM199309093291108

7. Senaratne,W.V. Outcome of treatment of multidrug resistant tuberculosis. Ceylon Medical Journal 2004;49(3):86-7.No doi

8. Magana-Arachchi DN, Perera AJ, Senaratne V and Chandrasekaran NV Pattern of drug resistance and RFLP analysis on Mycobacterium tuberculosis strains isolated from 
recurrent tuberculosis patients. Southeast Asian Journal of Tropical Medicine and Public Health. 2010;41(3):583-9 No doi

9. Rajapaksa, U. S., \&Perera, A. J. Sublineages of Beijing Strain of Mycobacterium tuberculosis in Sri Lanka. Indian Journal of Microbiology 2011;51(3):410-2 http://dx.doi.org/10.1007/s12088-011-0150-1

10. Bifani PJ, Mathema B, Kurepina NE, Kreiswirth BN Global dissemination of the Mycobacterium tuberculosis W-Beijing family strains. Trends in Microbiology 2002;10(1):45-52 http://dx.doi.org/10.1016/S0966-842X(01)02277-6

11. Johnson R, Warren R, Strauss OJ et al. An outbreak of drug-resistant tuberculosis caused by a Beijing strain in the Western Cape, South Africa. Int J Tuberc Lung Dis 2006;10(12):1412-14 No doi

12. Khoja, T.A. (ed.) Rules and Regulations for Medical Examination of Expatriates for Work in Cooperation Council States. Saudi Arabia: King Fahad National Library, 2005.

13. CARAM Asia. State of Health of Migrants, 2007. Mandatory Testing, 2007, p. 156.

14. Ministry of Health. General Manual for Tuberculosis Control. MOH, Sri Lanka Publications, 2005.

15. Ministry of Health. Country Report Card for the Health of Migrants Resolution. 2012. Ministry of Health and IOM publications. Weblink: http://www.migrationhealth.lk/

16. Arshad, S., Bavan, L., Gajari, K., Paget, S. N., \&Baussano, I. Active screening at entry for tuberculosis among new immigrants: a systematic review and metaanalysis. European Respiratory Journal 2010;35(6):1336-45. doi:10.1183/09031936.00054709

17. Fazlulhaq, N. Indians to work in Lankan fields. Sunday Times. February 24, 2013.http://www.sundaytimes.lk/130224/news/indians-to-work-in-lankan-fields-34464.html

18. Australian Government. Fact Sheet 22-The Health Requirement. National Communications Branch, Department of Immigration and Citizenship, Canberra. Last reviewed July 2013. http://www.immi.gov.au/media/fact-sheets/22health.htm

19. Government of Singapore.Medical Examination. Work Permit (Foreign Worker).Ministry of Manpower. Last reviewed July 2013. http://www.mom.gov.sg/foreign-manpower/passesvisas/work-permit-fw/when-you-apply/Pages/medical-examination.aspx

20. Ministry of Health. Sri Lanka National Migration Health Policy. MOH, Sri Lanka Publications, 2012.

21. Sri Lanka bureau of foreign employment annual report, 2010.

22. Abouzeid, Mohammad S., Alimuddin I. Zumla, ShazaFelemban, BadriahAlotaibi, Justin O'Grady, and Ziad A. Memish. "Tuberculosis trends in Saudis and non-Saudis in the kingdom of Saudi Arabia-a 10 year retrospective study (2000-2009)." PloS one 7, no. 6 (2012): e39478. doi:10.1371/journal.pone.0039478

23. Hannum, J. and Larson, H. A human rights approach to TB. World Health Organization Publications, Geneva, 2001.

24. International Organization for Migration. Migration Health Assessments in IOM. IOM Publications, Geneva, 2009. 